\title{
Vida y costumbres de los judeoconversos, según los procesos inquisitoriales $^{1}$
}

España conmemoró en 1992 el V Centenario de la efeméride del descubrimiento de América. Ante esta gesta, muy poco se ha dicho de otro acontecimiento que tuvo lugar en la misma fecha: la expulsión de los judíos y su obligada diáspora. De la importancia de dicha comunidad hispana dan fe sus aportaciones al pensamiento filosófico, a la literatura, astrología, medicina, etc. Según Gaspar Remiro, ssolamente hicieron la peregrina reserva de escribir la lengua adoptiva con las letras de su clásica originaria. Con los signos de su alifato redactaron nuestros moriscos el romance castellano y con sus grafias hebraicas lo escribieron y siguen escribiendo los judeo-españoles o sefarditas" ${ }^{2}$.

La antigua convivencia entre las comunidades cristiana y judía, en nuestro caso, se vio gravemente alterada con la creación de la Inquisición que intentaba extirpar todo elemento perturbador que afectara o pudiera afectar a la fe cristiana, y cuyo objetivo principal eran los seguidores de la religión mosaica. Por este motivo se les dio la oportunidad de optar por convertirse al cristianismo o salir de España, hecho este último que forzó a muchos a simular una conversión que en modo alguno estaban dispuestos a cumplir. Ello motivó la práctica privada de su religión de tan graves consecuencias para tantas personas.

A partir de esa determinación, la vida de los conversos fue objeto de especial atención por parte de los cristianos viejos: se analizaba no sólo lo que hacian o decían, sino también lo que dejaban de hacer o decir. Sabedores de que tendrían que dar cuenta de sus actos evitaban todo lo que pudiera suscitar sospecha de no osbervar la nueva fe que "voluntariamente habian aceptado. Todo ello les hacía vivir con el temor y el sobresalto de poder ser delatados en cualquier momento no sólo por sus enemigos, sino incluso por amigos y familiares de entre los que no debía excluirse a padres, hermanos y cónyuges.

1 Una versión resumida de este trabajo se expuso en el XXI Simposio de la Sociedad Española de Lingǘstica celebrado en Granada los días 16-19 de diciembre de 1991.

2 Matiano GASPAR REMIRO, sobre algunos vocablos y frases de los judeo-españoles., BRAE, I (1914), pp. 449-455, especialmente 449-450. 
Yolanda Moreno nos trae este penoso testimonio: Juana de Zaragoza fue procesada, ya difunta, acusada por sus hermanos Elvira y Fernando de ayunar el Día Mayor, guardar los viernes y sábados y no comer tocino "ni carne pelaguda" el 6 de diciembre de 1491. 3 .

Más patético aún, si cabe, es el testimonio acusador de una mujer conocida por la Panpana contra su marido: que al tienpo que alguno de los fijos que yo tengo nasçieron yo non los fade ni mande fadar, et sy se fadaron, que los mandaria e faria fadar Iohan Gonsales Panpan, su padre 4 .

Las acusaciones contra los judaizantes podían ser por motivos graves, por meras sospechas $\mathrm{e}$ incluso por nimiedades que, no obstante, causaban o podían causar en el mejor de los casos una situación embarazosa, o el suplicio, de confirmarse la acusación: «que no se sabe santiguar ni hazer Cruz, sino vn garauato poniendo la mano en la frente o en el hombro ysquierdo" s; .Item a Mosse Corredor, [...] por que dixo e acuso a Recien, [...], que se pixava en el orço" ${ }^{6}$; "vio este testigo como se dio çiertas vezes con amas manos sobre la barriga y no en los pechos como lo hazen los christianos al tienpo de consumir" "; "vio al dicho Gonçalo traer entre el jubón y el sayo vn habitillo destameña blanca con su cayrel de hilo negro o azul, y le paresçio de los que entre los judíos. ${ }^{8}$, etc.

De todos es también sabido cómo la Ley de Moisés establece que los nacidos varones han de ser circuncidados. Para evitar ser reconocidos como

3 Yolanda MORENO KOCH, "La comunidad judaizante de Castillo de Garcimuñoz: 14891492*, Sefarad, 37 (1977), pp. 351-371, p. 365.

+ Haim BEINART, Records of the Trials of the Spanish Inquisition in Ciudad Real, Edited with Introductions and Notes by ... I-IV (Jerusalem: The Israel of Sciences and Humanities, 1985), I, doc. 3, a. 1483, p. 77 , lín. 6.

' H. BEINART, Records, II, a. 1511, p. 93.

6 Beatrice LEROY, The Jews of Navarre in the Late Middle Ages (Jerusalem: The Magnes Press, The Hebrew University, 1985), doc. 34, a. 1384, p. 203, lin. 14.

- H. BEINART, Records, II, a 1511, p. 84.

8 Carlos CARrete PARRondo, Fontes Iudaeorum Regni Castellae. II. El Tribunal de la Inquisición en el Obispado de Soria (1486-1502) (Salamanca: Universidad Pontificia de Salamanca-Universidad de Granada, 1985), doc. 408, a. 1491, p. 169, lín. 5. En adelante FIRC II. El DRAE, s.v. cairel 2, lo define como 'Guarnición que queda colgando a los extremos de algunas ropas, a modo de fleco', advirtiendo que procede del catalán cairell (< 'Quadrellum). Corominas y PASCual, s.v., indican, en cambio, que cairel 'pasamano que adoma el borde de un traje o sombrero', diminutivo de caire 'cantos, esquina' ( $<$ QUADRUM), cuya primera documentación se halla en inventarios aragoneses de 1497, es de procedencia occitánica. El cairel del texto es, provisionalmente, el primer testimonio documentado al preceder en seis años la fecha del DCECH. Elena PEZż MARTínez lo considera, sin embargo, de origen árabe; véase $E l$ atavio hispano-ánabe: La berencia de su nomenclatura en la España cristiana (Granada: Resumen de tesis doctoral de la Universidad de Granada, 1979), núm. 253, pp. 1-64, especialmente p. 63. 
judíos, se cuidaban de mostrar las partes pudendas aunque, a veces, la casualidad o la desgracia les impedía guardar el secreto. En estos casos, alguna de las explicaciones sobre el hecho de estar circuncidado no deja de ser ingeniosa de no vivir en una época en que una circunstancia de esta índole pudiera conducirlo a la hoguera: e le bió este testigo sus sesto mienbro, e estaba retajado; e le preguntó este testigo que qué abía seydo aquello, e le dixo que siendo niño cayera de un tablado e se lo rompiera el capillo, con una costilla* .

Los considerados culpables por la Inquisición hubieron de llevar corozas. Sebastián de Covarrubias define la voz como *El rocadero hecho en punta, que por infamia y nota ponen a los reos de diversos delitos", al tiempo que señala a quién se le aplicaba: "El Santo Oficio saca con conoças a los que han de ser relaxados, a los casados dos vezes, a los hechizeros y a otros reos, conforme a la gravedad de sus delitos. Los demás juezes a los cornudos, a las alcagüetas y a otros delinqüentes. [...] ${ }^{10}$. Y el DRAE (s.v. coroza): 'Capirote

9 C. CarRete Parrondo, FIRC, II, doc. 107, a. 1488, p. 64, lín. 6. El DCECH, s.v. capullo, dice que capillo no se usó en la literatura con el significado de 'prepucio' hasta el siglo XVI. En la obra de John M. HILL, "Universal Vocabulariom de Alfonso de Palencia. Registro de voces internas (Madrid, 1957), s.v. capillo, se dice: 777 d. circuncisión. Voz que (s.v. circuncisión) define: "77d Circuncisio es cortadura del capillo del miembro viril usada entre los iudios". C. J. CELA, Diccionario secreto. 2. Segunda parte. Series pis y afines (conclusión) (Madrid: Alianza, 1971), s.v. capillo, p. 491, afirma que capillo “Es met. formal (el prepucio semeja un capillo, capucha).

10 Sebastián de COVARrubias, Tesoro de la Lengua Castellana o Española según la impresión de 1611, con las adiciones de Benito Remigio Noydens publicadas en la de 1674. Edición preparada por Martín de Riquer (Barcelona: Editorial Alta Fulla, 1989), s.v. coroça. En un poema de origen anónimo donde se describe la evolución de la mujer, se dice:

De quince a veinte es niña; buena moza de veinte a veinticinco, y por la cuenta gentil mujer de veinticinco a treinta, ¡dichoso aquel que en tal edad la goza!

De treinta a treinta y cinco no alboroza mas se puede comer con sal pimienta, pero de treinta y cinco hasta cuarenta, anda en víspera ya de una coroza.

A los cuarenta y cinco es bachillera gansea, pide y juega del vocablo: cumplidos los cincuenta da en santera:

a los cincuenta y cinco hecha retablo, niña, moza, mujer, vieja, hechicera, bruja y santera, se la lleva el diablo.

Luis Rosales, Poesía española del Siglo de Oro (Madrid: Salvat, 1970), núm. 115, pp. 104-105. La tensión motivada por la existencia de la Inquisición era tal que un escritor de 
de papel engrudado y de figura cónica, [...], que como señal afrentosa se ponía por castigo en la cabeza a ciertos delincuentes [...]' ${ }^{11}$.

En un texto se recoge la variante conota - término metafórico que hace referencia a una planta conocida por 'cresta de gallo' o 'gallo-cresta' por su semejanza con la coroza-, cuya existencia desconoce el DCECH: "mandamos que en pena e penitençia de lo susodicho a la dicha Catalina de Çamora sea puesta vna mordaza en la lengua e vna corota en la cabeça e le den çien açotes publicamente" ${ }^{12}$.

Si el converso se reconciliaba con la Iglesia, el Tribunal del Santo Oficio le imponía como penitencia llevar durante un tiempo el sambenito: 'Capotillo o escapulario que se ponía a los penitentes reconciliados por el tribunal de la Inquisición' (DRAE, s.v.). Buena prueba de ello es el siguiente pasaje: "cuando la Ynquisiçión estaua en esta villa, se reconcilió Pedro de Madrid, vallestero, [...], e que le mandaron traer vna loba con vna + delante e otra detrás, e que así la traya ${ }^{13}$.

El sambenito era también conocido por dos cruzes, según prueban los siguientes testimonios: "y con Sant Benito de dos cruzes. ${ }^{14}$; "e amenazaron a la dicha Ynes Lopez, diziendo la dicha Leonor Gomes: ¿Fueses a alquilar la casa, doña, entre dos cruzes? ${ }^{15}$.

Buena prueba del escamio a que conducía llevar dicho ropaje, cuya vergüenza trataban de evitar los así condenados, lo proporciona el siguiente dato: que cubría el Sant Benito con las aldas del manto, ansy de la parte trasera como de delante ${ }^{16}$.

La afrenta de ser reconocidos como judaizantes les llevaba a intentar vengarse de los cristianos acusándolos de conversos ante la Inquisición:

finales del siglo XVII (a. 1686) escribe estas durísimas palabras: ‘pero el ynquisidor no busca sino el cómo a de prender, condenar, matar, encorozar, azotar, quemar, ensanbenitar y robar" (Maxim P. A. M. KHERKHOF, .La "Ynquisiçion de Luzifer y visita de todos los diablos", texto desconocido de Antonio Enríquez Gómez. Edición de unos fragmentos", Sefarad, 38 (1978), pp. 319-331. La cita se encuentra en la p. 326.

" El DCECH considera que coroza probablemente proceda del lat. CROCEA -ORUM, 'vestido de color de azafrán', cuya primera documentación data de 1465-73 (Coplas del Provincial).

12 H. BEINART, Records. I, doc. 74, a. 1484, p. 422.

13 C. Carrete Parrondo, FIRC, II, doc. 298, a. 1501, p. 128, lín. 4. Para el origen de "sambenito", cfr. Américo CASTRO, -Sambenito, RFE, XV (1928), pp. 179-181. Lo conocido por loba no es otra cosa que la vestimenta llamada bopa, esto es: 1) 'Especie de vestidura, al modo de túnica o sotana cerrada'; 2) Loba o saco de los ajusticiados' (DRAE, s.v. bopa).

14 H. BEINART, Records, II, a. 1511, p. 84.

15 H. BEINART, Records, II, a. 1512, p. 107.

16 H. BEINART, Records, II, a. 1511, p. 97. 
-porque los que son o hayan seydo erejes son enemigos de los christianos, y como se vehen en carçeles e son sambenitos, querian e deseavan a todos asy y lo procuran" ${ }^{17}$, o por cualquier otra circunstancia: "A la segunda pregunta dixo que sabe que tyenen enemistad por vn real e por vna caldera e por vna poca de çera e por vn çinto ${ }^{18}$; $Y$ Y ansymismo thenia grande henemistad a la dicha Maria Gonsales, mi muger, sobre que le dio la dicha mi muger a haser çiertas mitas e se las nego ${ }^{19}$.

Pero ante las pruebas en contrario de los inquisidores, los reos no tienen más remedio que retractarse: e que vn sabado, en casa de Rodrigo de Chillon, holgaron e comieron habas, e que todo lo otro que dixo della lo dixo porque la queria mal, que es muy mala hembra e fantastiga. 20 .

De lo que no hay duda es que, incluso con anterioridad a los hechos que comentamos, los judíos hubieron de soportar todo tipo de vejámenes. Los del Reino de Mallorca (siglos XII y XIV) y de Toledo (siglo XV), entre otros, se vieron sometidos a la humillación de llevar un distintivo en sus vestimentas que los delataba como tales: "A tots los jueus, [...], que degen portar una roda als pits la meytat vermella e l'altra meytat grogan ${ }^{21}$; •y si judío, en el tabardo puesta la sennal colorada, y si judía, en el manto" ${ }^{22}$; "traygan la sennal [...], que era de panno colorado cosido en el honbro con hilo, no prendida con alfileles (sic) y ellas en el honbro del manto. ${ }^{23}$.

17 H. BEINART, Records, II, a. 1513, p. 348.

18 H. BeINART, Records, I, doc. 86, a. 1484, p. 603. Para CoROMINAS y PASCual, cinto aparece por vez primera en el Vocabulario de Alonso de Palencia (1490). El testimonio citado es, pues, anterior en seis años a lo indicado por los autores del Diccionario.

19 H.BEINART, Records, II, a. 1513, p. 452. El DRAE define mitán como 'Lienzo para forros de vestidos, holandeta, holandilla'. Para el DCECH, que s.v. mitán nos remite a bolanda 'lienzo fino', su primera documentación se halla en Nebrija. Olanda, sin embargo, ya se documenta en 1483 según atestigua $M^{{ }^{2}}$ del Carmen MARTINEZ MElÉnDEZ, Los nombres de tejidos en castellano medieval (Granada: Universidad de Granada, 1989), pp. 506-507, en donde, por otra parte, nada se dice de la posible equivalencia de mitán y bolanda.

20 H. BEINART, Records, II, a. 1513, p. 302.

21 A. PONS, Los judíos del Reino de Mallorca durante los siglos XIII y XIV (Palma de Mallorca: Miquel Font, Editor, 1984), I, doc. 69, a. 1393, p. 279, lín. 8.

22 Pilar LEÓN TELLO, Judíos de Toledo. Tomo I. Estudio bistónico y colección documental (Madrid: CSIC, 1979), doc. 32, a. ¿1451?, p. 418, lín. 23.

23 P. LEÓN TELLO, Judios de Toledo, I, doc. 32, a. ¿1451?, p. 418, lín. 5. No hay duda del uso del significante alfileles si tenemos en cuenta que el oficio medieval alfilelero deriva de la variante alfilel. Sobre su empleo en el siglo XVI, ver Elena PEZzI, El Vocabulario de Pedro de Alcalá (Almería: Editorial Cajal, 1989), s.v. alfilel, p. 43. Para un estudio más pormenorizado véase mi artículo "Acerca de algunos oficios medievales", Actas del Congreso de la Sociedad Española de Lingüústica XX Aniversario (Tenerife, 2-6 de abril de 1990), Edición al cuidado de M.2 Ángeles Álvarez MARTtinEz (Madrid: Gredos, 1990), pp. 372-381; especialmente 373-376. 
Orden que también se hizo extensiva para los seguidores de la religión musulmana: "y sus vestidos si son moros, con la luna turquesada en los tabardos y capuces" ${ }^{24}$.

La animadversión hacia los judíos y los mahometanos fue gradualmente creciendo. En el Ordenamiento de las Cortes de Burgos (1315) enviado al concejo de Alba de Tormes se disponía, entre otras cosas, que moros y judíos no pudieran llevar en adelante nombre de cristianos; así como la tajante prohibición de que éstos no sólo no convivieran con los de otras religiones, sino que tampoco cuidaran ni se hicieran cargo de los hijos de slos infieles", etc. ${ }^{25}$.

La situación llega hasta el extremo de que el Papa Benedicto XIII (1415) prohibe que los judíos encuadernen libros en los que aparezca el nombre de Cristo o de la Virgen ${ }^{26}$, hecho que dio lugar a que no pudieran ejercer su oficio numerosos encuadernadores y, por extensión, otros menestrales (orfebres, plateros, etc.) dedicados a la creación de objetos artísticos propios del culto cristiano: cálices, cruces, custodias, etc.

En Navarra incluso se les prohíbe salir y trabajar en domingo hasta después de celebrada la misa; prohibición de la que se excluía al los médicos o los que visitaban enfermos, entre otros:

ordenando e mandando [el rey de Navarra] que en nengunos Domingos ni dias de fiesta i despues que la Sancta Madre Iglesia celebra, los ditos Judios ni algunos dellos no hayan de sallir de sus Juderias ni andar por las calles entre los Christianos fasta que todo el officio sea fecho, es asaber fasta medio dia. Excepto los medicos e cirurjanos e aquellos por visitar dolientes o por otra evidente necessidat ${ }^{27}$.

A los cristianos nuevos también se les privó de la posibilidad de ejercer cargos públicos ${ }^{28}$, aunque dicha orden llegó a ser revocada en algunos

24 P. LEON TELlo, Judios de Toledo. I, doc. 32, a. ¿1451?, p. 418, lín. 21. Según el DCECH, el adjetivo de color turquesada se documenta por vez primera en Nebrija. Ante el dato aportado, será necesario adelantar su datación.

25 Cf. A. Barrios Garcia, A. Martin EXPóstTo, G. del Ser QuiJano, Documentación medieval del Archivo municipal de Alba de Tormes (Salamanca: Edic. de la Universidad de Salamanca - Excmo. Ayuntamiento de Alba de Tormes, 1982), doc. 25, a. 1315, p. 80.

26 Cf. Fritz (YITZHAK) BAER, Historia de los judios en la Comona de Aragón (s. xiii y xiv). Traducción por Antón Sanmartín Rivera (Zaragoza: Diputación General de Aragón. Departamento de Cultura y Educación, 1985), p. 187, nota 24.

27 B. LEROY, .Le royaume de Navarre et les juifs aux xiv et $x v^{\circ}$ siècles: Entre l'accueil et la tolerancen, Sefarad, 38 (1978), pp. 261-292; apéndice documental n. ${ }^{\circ}$ VII, a. 1492, pp. 291-292.

28 Cf. Nicolás LOPEZ MARTINEZ, Los judaizantes castellanos y la Inquisición en tiempo de Isabel la Católica (Burgos, 1954). El autor indica que el rey Enrique IV se lo prohibe a los conversos de Córdoba (pp. 66-67), Toledo y Ciudad Real (pp. 73-74). Véase más información sobre la cuestión en los Apéndices II, :Traslado de una carta de privilegio...., 
lugares: Juan II, el 13-VII-1444, según el canónigo toledano Pedro de Salazar y Mendoza, concede un privilegio para que los cristianos nuevos de Guadalajara pudiesen ejercer oficios públicos en la ciudad. 29 .

Con el fin de que los judeoconversos reconocieran su ficticia conversión a la fe cristiana y llegar a conocer quiénes de entre ellos judaizaban, los inquisidores los sometieron a indecibles torturas. Los principales tormentos empleados fueron los de la garrucha y el del potro, también conocido por el de la toca o tortura del agua, entre otros.

Las normas dictadas para llevar a cabo los suplicios eran sumamente minuciosas. El inquisidor ordena que debe anotarse escrupulosamente el comienzo del tormento, así como todo lo que se haga y se diga durante el interrogatorio:

Hase de asentar todo lo que el reo dixere, [...], cómo lo mandan poner en el potro, y ligar piemas, cabeça y braços: [...]. Si lel tormentol es de garrucha, se ha de assentar cómo se pusieron los grillos, y la pesa, o pesas, y cómo fué levantado, y quántas vezes, y el tiempo que en cada una lo estuvo. Si es de potro se dirá cómo se le puso la toca y quántos jarros de agua se le echaron y lo que cabía en cada vno... ${ }^{30}$.

Del tormento de la toca tenemos el siguiente testimonio: e por la cabeça puesto vn cordel e apretado, e pvesta vna toca delante la cara, e [con] vn jarron que cabia tres quartillos, poco mas o menos, le començaron a dar agua" ${ }^{31}$.

p. 386, y XI «Pragmática sobre los hijos de penitenciados por la Inquisición" del año 1501, pp. $427-428$, de la misma obra. Tampoco se les permitió llevar armas, cabalgar, vestir seda, etc., ver Bernardino Llorca, "La Inquisición española y los conversos judíos o "marranos", Sefarad, 2 (1942), p. 127, nota 5.

29 Francisco Cantera Burgos y C. CARRete PARrondo, "Las juderías medievales en la provincia de Guadalajara., Sefarad, 34 (1874), pp. 43-78, especialmente p. 54.

30 N. LOPEZ MARTINEZ, Los judaizantes castellanos. La cita corresponde al texto de la nota 192, p. 345.

31 H. BeINART, Records, II, a. 1494, p. 33. Este tormento dio lugar a la expresión sefardí ‘Bever la toka. 'sufrimiento', 'martirio', usado por muchos con desconocimiento de su verdadero sentido. Véase la explicación ofrecida por el Dr. Eli Shaul en su artículo -Bever la toka", Aki Yerushalayim, 41 (1990), p. 47. En el léxico del marginalismo del Siglo de Oro aún se recuerda el tormento llamado "del ansia":

-Comiença la Clariosa

a remojalle los labios

llevando tras sí el cendal vaziando apriessa el Pitaflo.

El laque viendo tal ansia, y que no parava un rato, pide que el Bramante afloxen que quiere cantar de plano.*

(HILL, 89, 452, XXXII) 
Para llevarlo a cabo; pues, sa víctima era atada sobre un bastidor, la forzaban a abrir la boca y se le metía una toca o paño por la boca hasta la garganta para obligarle a tragar agua vertida lentamente de un jarro. La severidad de la tortura variaba de acuerdo con el número de jarros de agua empleados: ${ }^{32}$.

\section{LA ALIMENTACIÓN}

Conocer el tipo de alimentación de las pesonas era una de las maneras de inferir si se era o no judaizante. Como es bien sabido, la Ley de Moisés prohibía alimentarse de animales considerados impuros (Levítico, 11-20): cerdo, liebre, conejo, etc., así como de los productos derivados de ellos: e que al tienpo que avia verengenas, la dicha su ama le hazia coser a este testigo las verenjenas e freyrlas en azeyte y las hechaua en la olla con la carne, syn toçino" ${ }^{33}$; Iten, sabe que non [se] comia en aquella casa conejo ni liebre, e que la carne que auian de comer, que la purgaua antes que la comiese[n] ${ }^{34}$; "Y vn dia, comiendo con su marido de vn pedaço de puerco javali, y este testigo le dixo: Señora, ¿pues no venis a comer? Y ella dixo: No puedo comer agora" ${ }^{35}$; "que un dia de Carnestolendas tenia hechas fojuelas con manteado puerco et non quiso comer dellas ni menos queria comer toçino" ${ }^{36}$.

Los animales acuáticos sin aletas y sin escamas también les estaban vedados: "nunca les vio comer pulpo, ni anguila, ni otro ninguno pescado syn escamas ${ }^{37}$.

No había problema, en cambio, si se alimentaban de pescados con escamas: «vn sábado que comieron todos, a la çena, baruos e pescado,

El texto lo recojo de José Luis ALONSO HERNÁNDEZ, El lenguaje de los maleantes españoles de los siglos XVI y XVI: la germanía (Introducción al léxico del manginalismo) (Salamanca: Ediciones Universidad de Salamanca, 1979), p. 191, s.v. pitaflo 'jarro'. Más datos sobre las diferentes formas de tortura ofrecen Guy TESTAS et Jean TESTAS, L'inquisition (Paris: Presses Universitaires de France, 197433), pp. 38-41 y 78-79.

32 Ricardo GarCfa CARCEL, La Inquisición (Madrid: Biblioteca El Sol, 1991), p. 44.

3. H. BEINART, Records, II, a. 1511, p. 491.

34 H. BEINART, Records, I, doc. 3, a. 1483 , p. 85, lín. 19.

35 H. BeINART, Reconds, II, a. 1494, p. 21.

36 H. BEINART, Records, II, a. 1494, p. 24. El DCECH (s.v. boya) deriva boyruela de boya, pero no la define ni indica el año de aparición. Para el DRAE, bojuela es 'fruta de sartén, muy extendida y delgada', definición que sin duda recoge del Tesoro de Covarnubias (s.v. bojuelas).

37 H. BeInART, Records, II, a. 1511, p. 164. 
e Diego de Roa con otros veçinos de Aranda comieron e çenaron buenos pollos" 38 .

Por el contrario, observar que una persona consumía todo tipo de alimentos era signo de no pertenecer a la religión mosaica: «E que algunas vezes ayantavan carne e a la noche çenauan congrion ${ }^{39}$; e otras aves de qualesquier otras raleas que fuesen, e de todos pescados, anguila, lanpreas, camarones, tollo e pulpo e congrio [...]" 40 .

De los animales terrestres que no les estaban vedados podian alimentarse siempre y cuando hubieran sido sacrificados según ordenaba la Ley de Moisés: «Dezia en muchas vezes: Sy, os queda vna piema. E otras veses: Vnas agujas. E otras vezes desía: Oy no quedo nada; para otro dia lo guardare ${ }^{41}$; «e bido estar al fuego una olla cociendo con unas abujas de carnero ${ }^{42}$.

Una de las comidas habituales de los judaizantes era la adafina. Alfredo Juderías dice que "Era el guiso más característico de la cocina hispano-judia: una especie de nuestro cocido para los hebreos que, allá por el siglo xv, hacían al anochecer del viernes para tomarlo el sábado ya que ese día, como sabemos, estaba rigurosa y ritualmente prohibido trabajar, guisar e incluso encender fuego ${ }^{43}$. Preparar así la comida era signo de ser judío o judaizante, y por ello en los juicios inquisitoriales era lo primero alegado por los testigos contra todo converso sospechoso: "la muger de Herrand Martines, trapero, defunto, vecina de Soria, que enbió en sábados a este testigo que le diesen de adafina, e queste testigo nunca ge lo quiso dar, escusándose ${ }^{44}$.

Dicha comida podía ser de carne, legumbres y verdura - todo muy bien condimentado-; pescado y verdura, huevos y queso, etc., según se desprende de los siguientes testimonios: "e que otra vegada le dieron a comer de vna cosa que era guisada con muchas espeçias, e que dezian que era

\footnotetext{
38 C. CARREte Parrondo, FIRC, II, doc. 425, a. 1486, p. 174, lín. 4.

39 C. CARRETE PARRONDO, FIRC, II, doc. 14, a. 1490, p. 25, lín. 8.

40 H. BEINART, Records, I, doc. 5, a. 1483, p. 97, lin. 3.

41 H. BEINART, Records, I, doc. 85, a. 1484, p. 574. El DRAE define aguja (acep. 31) como 'Costillas que corresponden al cuarto delantero del animal'. El DCECH no recoge este significado.

42 C. CARrete Parrondo, Fontes Iudaeroum Regni Castellae III. Proceso inquisitorial contra los Arias Dávila segovianos: un enfrentamiento social entre judios y conversos (FIRC. III) (Salamanca: Universidad Pontificia de Salamanca-Universidad de Granada, 1986), doc. 63 , a. 1487, p. 41 , lín. 4.

43 Alfredo JUDERIAs, Viaje por la cocina Hispano-Judia (Madrid: Editorial Seteco, 1990), p. 17. Para el DCECH, adafina (<ár. dafina 'oculta, sepultada') es un guiso elaborado la noche del viemes para consumirlo el sábado.
}

44 Carrete Parrondo, FIRC, II, doc. 2, a. 1490, p. 17. 
adafina ${ }^{45}$; que esta confesante bio en casa de Juana Gonsales, muger de Juan Lovon, [...] que la susodicha guisaba de comer pescado e verengenas vn viemes para el sabado "46; que merendavan aquellos dias de sabados vnas caçuelas guisadas de viemes antes, hechas de huevos e queso e perexil e culantro e espeçias" ${ }^{47}$; "e que merendauan aquellos dias de sabados vnas caçuelas guisadas de viernes antes, hechas de huevos e queso e perexil e calantares y espeçias, e que algunas vezes las hazian de verenjenas e otras vezes de çanahorias" ${ }^{48}$.

Como sinónimos de adafina se empleaban caliente y bamin ( $<$ heb. bammin): „Oyslo, Çinaha, catad que hagáys para mañana buen calyente, $\mathrm{e}$ que traya hasta carne, porque me avéys de enbiar dél" ${ }^{49}$; "vio muchas veses que comía came en los biemes e pasteles e caçolejas [sic] de carne e hamin que ge lo daba Abrahén Romín 50.

En otro pasaje se habla de sal pimentada: *e comieron vna sal pimentada que ellos dezian como caçuela e vnas sardinas, la sal pimentada del dia antes" ${ }^{51}$.

También era habitual comer albondiguillas o "carne picada y sazonada con especies" (sic) (Covarrubias, s.v. albóndiga): "Ansimismo dixo que este testigo y Juana su muger, comieron albondiguillas algunas veçes, e las haçía en su casa este testigo" 52.

45 H. BEINART, Records, I, doc. 5, a. 1483, p. 115, lín. 24.

46 H. BEINART, Records, II, a. 1511, p. 75.

47 H. BEINART, Records, II, a. 1511, p. 479. Culantro = cilantro. El Diccionario académico lo define como 'Hierba de la familia de las umbelíferas, [...], aromática y de virtud estomacal'.

48 H. BEINART, Records, II, a. 1511, p. 251. Calantares debe ser variante del culantro citado en la nota anterior. También se documenta la variante culantron: porque sienpre acostunbravan [...] guisar los dichos viernes para los sabados caçuelas de pescado e sardinas, e a las vezes con verengenas e con çebollas y culantron y espeçias, e las comian en los dichos sabados siguientes" (H. Beinart, Records, II, a. 1511, p. 163).

49 C. CARRETE PARRONDO, FIRC. II, doc. 57, a. 1490 , p. 40, lín. 3. De nuevo aparece en las líneas $6,11,20$ y 23.

so C. CARREte Parrondo, FIRC, II, doc. 368, a. 1502, p. 152, lín. 2. Según el DCECH, cazoleja se documenta por vez primera en La verdad sospechosa de Ruiz de Alarcón. Ahora bien, si el dramaturgo nacido en México (1581?-1639) escribió la obra en torno a 1624, será preciso adelantar la datación de cazoleja 122 años, a tenor de la documentación aportada. He tomado los datos de J. RUIZ DE ALARCón, Teatro. Prólogo y notas de Alfonso Reyes (Madrid: Espasa-Calpe, 1961), p. 261. Sobre la equivalencia de bamin y adafina ver Y. BAER, Historia de los judios en la España cristiana, traducida del hebreo por José Luis Lacave. Segunda Parte. De la catástrofe de 1391 a la Expulsión (Madrid: Altalena Editores, 1981), p. 528.

51 H. BEINART, Records, II, a. 1503, p. 135.

52 C. CARRETe PARRONDO, FIRC. III, doc. 146, a. 1490 , p. 84, lín. 14. Para el DCECH, albondiguilla se documenta en 1599. La fecha hay que adelantarla 109 años. 
La elaboración de los alimentos se llevaba a cabo en la cocina, de la que Covarrubias (s.v. cozina) dice: -Coquina; donde se guisa la comida y se cuezen las ollas; algunas vezes se toma por el caldo. El Diccionario de Autoridades menciona entre sus acepciones las de 'potaje' y 'caldo', y el DRAE (s.v. cocina 3) «Potaje o menestra que se hace de legumbres y semillas; como garbanzos, espinacas, etc.n. Las definiciones de los diccionarios parecen atenerse a los antiguos valores de 'potaje' y 'caldo' del vocablo cozina: e que luego le rogó [...] Manuel Rodrigues a este testigo que le diese alguna cosa que comiese aquel testigo le dio vna poca de cozina y que no le quiso dar carne" ${ }^{53}$; "E que vio vn viernes en la noche que mataron vna gallina $e$ comieron las tetiellas e guardaron la cosina para otro dia sabado" ${ }^{44}$.

Como se ha dicho anteriormente, un motivo para manifestar que no se era judaizante era revelar que entre sus alimentos no faltaban los prohibidos por la religión mosaica: tocino, anguilas, congrio, etc.: ssy saben, etc., que yo syenpre comi perdizes e conejos [...] e pulpo e congrio e lanpreas e anguillas e toçinom 55 .

53 C. Carrete PARRONDO, FIRC, II, doc. 82, a. 1491, p. 48. Para Carrete, cozina es el 'potaje de legumbres y semillas'. Creo que podría interpretarse mejor como 'caldo'.

54 H. BEINART, Records, I, doc. 83, a. 1484, p. 546. En este caso creo que no hay duda del significado 'caldo'. El DCECH (s.v. teta) documenta en portugués tetela [1384] lo que hoy es titela 'carne del pecho de la gallina o del palomo'. En el Libro de la caça de D. Juan Manuel ([c.v.] p. 192, lín. 11) se documenta tetiellas 'pechugas': "deven encarnar el sennuelo con dos tetiellas o con dos piernas de buena gallina. Dado que la crítica piensa que D. Juan Manuel escribe esta obra entre los años 1325 y 1338 nos encontramos ante la primera aparición del vocablo. Por tanto, si tomamos como punto de referencia el último año, esto es, 1338, es preciso adelantar 46 años la primera datación de tetiellas. La obra citada forma parte de Cinco Tratados. Libro del cavallero et del escudero. Libro de las tres razones. Libro enfenido. Tractado de la asunción de la Virgen. Libro de la caça. Edición, introducción y notas de Reinaldo Ayerbe-Chaux (Madison, 1989).

55 H. BEINART, Trujillo, a. 1489, p. 295, X XIIII. A mi parecer, anguila y anguilla son soluciones populares que desde antiguo se encuentran en documentos castellanos, leoneses $y$, en algún caso, riojanos:

Anguila *Et Resa, per omnes domus, singulas arenzadas de anguilas (A. UBIETO, Cartulario de San Millán de la Cogolla (759-1076), Valencia, Anubar Ediciones, 1976, doc. 22, a. 934, p. 38, lín. 23). El autor considera más probable que el documento corresponda a los años 1140-1143. *et per Pelagum Anguilarium. (Colección diplomática del monasterio de Belmonte. Transcripción y estudio por Antonio C. Floriano, Oviedo, CSIC, Instituto de Estudios Asturianos, 1960, doc. 10, a. 1142, p. 79, lín. 4). El texto se encuentra en una copia de los siglos XII/xalı. "e de todos pescados, anguila, lanpreas, camarones, tollo e pulpo e congrio [...]. (H. BeINART, Records, I, doc. 5, a. 1483, p. 97, lín. 2, y p. 109, lín. 37). "nunca les vio comer pulpo, ni anguila, ni otro ninguno pescado syn escamas(H. Beinart, Records, II, a. 1511, p. 164). 
En ocasiones empleaban metáforas para hablar de un determinado animal de carne muy apreciada: en tiempo de quaresma [...] le mandaban que fuese a la judería por pulpo de prado, y este testigo les decía que qué cosa era pulpo de prado, y los dichos le respondían que allá ge lo dirían. ${ }^{56}$.

La solución del acertijo nos la da el siguiente pasaje: eque aquello era el pulpo que le mandaban traer y los susodichos le respondían que era necio, que agora sabía que aquello era pulpo de prado, que las obejas y carneros ¿no sabía que pacían en el prado?, ${ }^{57}$.

Uno de los productos elaborados con la carne del cerdo y de otros animales era el malcozinado ${ }^{58}$, del que Simonet dice: "malcozinado tripas" [...] Probl. del Lat. farcimen (voc. derivado de farcio, rellenar, embutir), que significa tripa rellena de carne picada, como salchichón, chorizo, etc., cuyo nombre aplicado primeramente á las tripas, callos y menudo de las reses

\footnotetext{
Anguilla * "et dono uobis, canonicis eiusdem ecclesie, totam meam uineam quam habeo in Aguilar, [...], ad latus de Petro Abbate [...] et de Petro Pesquero et de illa carrera de rio de Anguillas. (J. M. GARRIDO GARRIDO, Documentación de la catedral de Burgos (804-1183), Burgos: Ediciones J. M. Garrido Garrido, 1983, doc. 194, a. 1175, p. 308, lin. 6). * Et super hoc do uobis et concedo ut habeatis quartam partem de omnibus anguillis quae exierint de lacu et decimam ecclesie. (Justiniano Rodríguez, Los Fueros del Reino de León. II. Documentos, León, Ediciones Leonesas, [1981], doc. 65, art. 4, a. 1213, p. 195, líns. 14-15). *Esta es el abenencia qe faz el abbadessa de Uillaenna con Pedro Felizes: a a uenir Pedro Felizes a rio de Anguiellas [...]. (R. MENÉndez PIDAl, Documentos Lingüústicos de España. I. Reino de Castilla, Madrid, Centro de Estudios Históricos, 1919, doc. 47, a. 1223, p. 76, lín. 6. Vileña, Partido de Briviesca -Burgos-). Ambas soluciones continúan aún vigentes en Andalucía: en la zona occidental predomina anguilla; en la oriental, anguila. La provincia de Almería sólo conoce anguila. (Cf. M. Alvar con la colaboración de A. LLORENTE y G. SALVADOR), Atlas Lingüístico y Etnográfico de Andalucía. Tomo IV, Universidad de Granada, CSIC, 1965, s.v. anguila. lám. 1084, mapa 1145). Idénticos resultados se dan en Colombia: anguila en Antioquia 61 (Rionegro); anguilla en Antioquia 32 (Frontino) y Choco 6 (Cértegui). (Cfr. R. TORRES QUINTERo (director), Atlas Lingüístico-Etnográfico de Colombia, T. VI, Bogotá, Instituto Caro y Cuervo, 1983, nombres de peces (1), mapa 105). Sobre esta cuestión, véanse los artículos de José MONDÉjAR, :Notas de ictionimia fluvial., Estudios ofrecidos a Emilio Alarcos Llorach (Oviedo, 1979), IV, pp. 209-230; especialmente las páginas 210-215; .La función sintáctica como determinante de la estructura de dos categorías (?) gramaticales: el artículo y el pronombre", REL, 15/2 (1885), pp. 291-307.

So C. CARRETe PARRONDO, FIRC, III, doc. 157 , a. 1490 , p. 91 , lín. 8.

57 C. CARREte PARRONDO, FIRC, III, doc. 157 , a. 1490 , p. 91 , lín. 13 y ss.

so El DRAE (s.v. malcocinado) lo deriva de mal 'contrariamente a lo que es debido' y cocinar, y lo define como 'menudo de las reses.// 2. Sitio donde se vende'. Para CovarRubias (s.e. cozina) es el lugar donde se venden las morcillas y menudos de carnero cozidos*.
} 
(malcozinado), se extendería despues á los piés de las vacas y demás despojos de camicería" 59 .

Uno de cuyos significados tiene el malcozinado del siguiente pasaje: en la renta del alcauala de la came biua e muerta, e pescado fresco e salado, e cabritos e malcozinado ${ }^{60}$.

Carrete Parrondo parece identificarlo con el vocablo cababeas de los textos que a continuación se citan: «E que este testigo, bibiendo con ella, le vio comer cababeas. ${ }^{61}$; qque byuiendo este testigo con el lyçençiado maestre Bernal y con su muger vido que hazían [...] su muger cababeas de lyvianos de vaca e de cabeça de vaca y de las entrañas..." ${ }^{62}$.

\section{EL PAN Y LA REPOSTERIA}

En determinadas fiestas religiosas - la Pascua, por ejemplo-, los judeoconversos solían acompañar sus comidas con pan cenceño ${ }^{63}$, al ser

59 Fco. J. SIMONET, Glosario de voces ibéricas y latinas usadas entre los mozárabes (Amsterdam: Oriental Press, 1967) s.v. Hérqueme, p. 266. Del topónimo Malcozinado (Badajoz) da noticia el Libro de la Montería:

\section{a...] Et es la bozeria \\ por el camjno de Mal Cozynado \\ fasta la Fuente e Mal cozjnat \\ do.}

(Estudio y edición crítica del Libro de la Montería de Alfonso XI, por M." Isabel Montoya Ramírez, Granada, Servicio de Publicaciones de la Universidad de Granada, 1992, p. 620, líns. 11.482 y $11.483-84)$.

60 P. LEÓN TELLO, Judios de Toledo. T. II. Inventario cronológico de documentos (Madrid: CSIC, 1979), doc. 906, a. 1456, p. 307.

61 C. CARRete PARRondo y C. Fraile CONDE, Fontes Iudaeorum Regni Castellae. IV. Los judeoconversos de Almazän 1501-1505. Origen familiar de los Lainez (Salamanca: Universidad de Salamanca-Universidad de Granada, 1987), a. 1505, p. 23. De nuevo en la 30. En adelante, FIRC, IV.

62 C. CarRete ParRondo y C. Fraile Conde, FIRC, IV, doc. 39, a.1505, p. 37. Para livianos 'pulmón', 'bofes', cf. DRAE, s.v. liviano 5; DCECH, s.v. leve, p. 637; y Vicente GARCIA DE DIEGO, Diccionario Etimológico Español e Hispánico (Madrid: Espasa-Calpe, 19893), s.v. levis, p. 775 . El gramático Alejo Vanegas emplea liuiano como sinónimo de pulmón en su descripción sobre el valor de la $b$ : ‘La $\mathrm{H}$ no es letra: sino señal de huelgo que engrossece la vocal o consonante a quien se allegare; formasse de la suerte que diximos de la a. saluo que sale el huelgo de mas baxo que es desde el pulmon que se dize liuiano; [...]. (Recogido de A. SAlvADOR PLANS, .El grafema $b$ en los tratadistas del Siglo de Oro, Anuario de Estudios Filológicos, 5 (1982), pp. 167-189. El texto se encuentra en la p. 174). Carrete explica del siguiente modo lo que serían las cababeas sacrificado un buey, la cabeza se cocía con las entrañas que, una vez picadas y añadiendo diversas especias, se introducían en las tripas del animal y se dejaban curar.

63 Cenceño, según el DCECH (s.v.), significa 'delgado, enjuto', 'puro, sin mezcla', 'ácimo'; de origen incierto, aunque quizá provenga de Cincinnus. Su primera doc. es del s. XIII (ms. biblico escurialense I.j.8). 
preceptivo abstenerse de consumir pan con levadura. En los documentos, suele describírsele a aquél del siguiente modo: "comian de vnas tortas blancas como la nieve, desabridas, como olivadas, [...]. E que esta confesante no sabia que cosa era pan çençeño, y que agora cree esta confesante que lo deviera de ser" ${ }^{64}$; $E$ que la de Diego de Teba hazia vna torta blanquesca" ${ }^{65}$.

Distinto al cenceño era el llamado pan lyudo, esto es, el fermentado con levadura: «que enbió a este testigo e a otras dos moças al salyr de la dicha pascua con pan lyudo e vn cabrito e yeruas al castillo desta [...] çibdad. 66 .

Con pan cenceño y otras serie de ricos ingredientes se elaboraba un plato de repostería conocido por ormigos: "dixo que baya traher pan cenceño de la judería a casa de la dicha doña Elbira, e que facían dello ormigos e comía dellos e otros muchos de su casan ${ }^{67}$.

El DRAE (s.v. hormigos 3) lo define como 'Plato de repostería hecho generalmente con pan rallado, almendras o avellanas tostadas y machacadas y miel'. Corominas y Pascual consideran que el plato en cuestión primero hubo de tener el significado de 'gachas, comida hecha con trigo o maíz quebrantados o pan desmenuzado, cocidos con agua o leche' (DCECH, s.v. hormigos), y posteriormente plato de repostería. Para muchos sefardies actuales, el tipo de alimento llamado formigo consiste en una especie de sopa de leche y almendras machacadas" que con especial cuidado se le ofrece a la mujer que acaba de dar a luz, con el fin de aumentar la secreción de la leche maternan ${ }^{68}$.

Plato semejante al anterior, según el DRAE, era el conocido por nuégados. -E que otras muchas veces le llebó este testigo frutas de nuégados e de sartén e que lo daba al mismo Diego Arias" ${ }^{69}$. Aunque en ocasiones se encuentra

H. H. BEINART, Records, II, a. 1512, p. 276.

is H. BeInART, Records, II, a. 1513, p. 294. El DCECH documenta el adjetivo blanquisco en 1513, fecha en que también datamos la variante blanquesca del texto.

th C. Carrete Parrondo, FIRC, II, doc. 21 , a. 1490 , p. 28 , lín. 6.

67 C. CARRete ParRondo, FIRC. III, doc. 38 , a. 1486 , p. 32, lín. 6.

68 Cf. Michael Molho, Usos y costumbres de los sefardies de Salónica (MadridBarcelona: CSIC, 1950), p. 61. En la p. 2 del diario Ideal de Granada correspondiente al día 4-5-1990 se recogía en el apartado "Una receta de la cocina andaluza. el guiso titulado .Hormigas con habas", cuyos ingredientes eran "pimientos rojos secos, aceite de oliva, cebolla, tomate, patatas, habas frescas, harina, sal y perejil. Como podemos observar, en nada se asemejan a los bormigos medievales salvo en su aproximado título.

69 C. Carrete ParRondo, FIRC. III, doc. 152, a. 1490, p. 87, lín. 18. El DRAE (s.v.) dice que el nuégado es semejante al bormigo, esto es, 'Pasta cocida al horno, hecha con harina, miel y nueces [...]'. En la Vida de San Eustaquio. Comedia jesuitica del Siglo de Oro. Estudio, edición y notas por Agustín de la Granja (Granada: Secretariado de Publicaciones, 1982), se encuentra la forma nuégados (Primera parte, acto III, estr. 5055, p. 292). 
como nuézados: «dos tortas de nuezados, cada torta de mill nuezes [.... ${ }^{70}$; e las dichas dos tortas de nuezados e tabaque de fruta cada pascua. ${ }^{71}$.

Entre sus alimentos se menciona también un tipo de ensalada de nombre almendrada: este testigo la hizo desnudar e acostar en vna cama e le dio de vna almendrada, echa con lechugas e con otras cosas, e que la susodicha la comio e se acosto en su retrete del dicho palaçio ${ }^{72}$.

Muy apreciadas eran también las fojuelas 'fruta de sartén, muy extendida y delgada' (DRAE, s.v. bojuela 2) 'que vn día de Camestolendas tenia hechas fojuelas con manteado puerco et non quiso comer dellas ni menos queria comer toçino" ${ }^{73}$.

En Asturias, aún se conserva la variante fayuela 'frito de pasta fermentada, compuesto de harina, leche y azúcar, que se come por Carnaval' (DCECH, s.v. hoja), que también pervive entre los sefardies como 'pasta de harina de trigo trabajada con agua, huevo y azafrán, enrollada y cortada a tiras' ${ }^{74}$.

Tampoco faltaban los bojaldres, pasteles con los que se obsequiaba a los amigos. Ahora bien, la constante normativa con la que gradualmente las

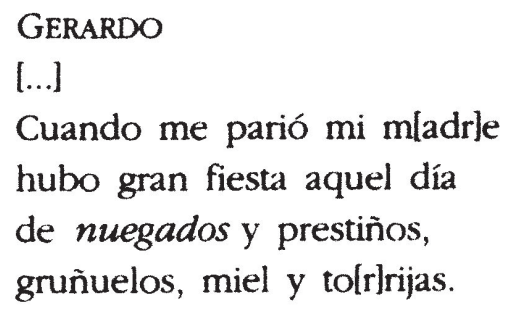

M. L. WAGNER, "Espigueo judeo-español, RFE, XXXIV (1950), pp. 9-106, s.v. nugada (p. 80), recoge en Bulgaria esta forma -esp. nogada- con el significado de 'salsa de nueces y especias con que se suelen guisar pescados' (Alemany). A. JuDERiAs, Viaje por la cocina Hispano-Judia, s.v. nugada, dice que es :Una salsa a base de nuez molida, miga de pan blanco y huevo batido.

70 P. LeÓn, Judios de Toledo, 1 , doc. 25, a. 1345, p. 402, lín. 5. CoRominas y PAscual (s.v. nuez) indican que nuégado aparece citado en Enrique de VIlLENA, Arte Cisoria, ed. de Navarro, cap. VI, p. 45, en el pasaje que dice: turrones, miegados, obleas, letuarios e tales cosas". Como ni el DCECH ni el DRAE hacen mención de nuézados es obligado considerarlo como la primera datación del vocablo.

71 P. LEÓN Tello, Judíos de Toledo, doc. 25, a. 1345, p. 402, lín. 12.

72 H. BEINART, Records, II, a. 1513, p. 580. La definición del Diccionario académico (s.v. almendrada) 'Bebida compuesta de leche de almendras y azúcar', en nada coincide con lo mencionado en el texto. El DCECH recoge el vocablo, aunque no lo define.

73 H. BeInART, Records, II, a. 1494, p. 24. Corominas-Pascual derivan bojuela de boja ( $<$ folia), término que Nebrija define como [ $\cdot h$. de massa tendida: laganum.].

74 C. BenarRoch, Ojeada sobre el judeoespañol de Marruecos", Actas del Primer Simposio de Estudios Sefardies (Madrid, 1-6 de junio de 1964), edición a cargo de lacob M. Hassán con la colaboración de M. ${ }^{2}$ Teresa Rubiato y Elena Romero (Madrid: CSIC, Instituto Arias Montano, 1970), pp. 273-275. Especialmente la p. 271. 
autoridades iban aislando a los judíos les conduce a prohibir el envío de este tipo de pasteles a los cristianos, así como convivir con ellos en determinados lugares públicos: que no se bañen en los baños con los cristianos ni les envien bojaldres" ${ }^{75}$.

\section{Costumbres RITUALES}

Hemos indicado anteriormente que el fiel seguidor de la religión mosaica sólo podía comer de aquellos animales sacrificados según estipulaba su Ley; esto es, degollados cumpliendo determinadas normas y con extracción total de la sangre por considerar que en ella estaba la vida (Lev. 17-11, 14). Por ello desechaban los animales cuya muerte se debiera a ahogamiento, o no hubiera sido realizada según las normas rabínicas. La carne de los animales sacrificados de acuerdo con la Ley era considerada caser; la que no cumplía este requisito recibía el nombre de truphá, trefé o trefá, entre otras variantes.

Para matarlos debían seguir, pues, el ritual llamado shebitá que, por su complejidad o desconocimiento, los judíos se abstenían normalmente de realizar. Carrete cita las palabras con que Alonso de Zamora, converso del siglo xv y catedrático de hebreo de la Universidad de Alcalá de Henares, explica ante el Tribunal de la Inquisición las circunstancias en que la carne era considerada trefé:

La res avia de ser muerta a mano de judio y degollada con cuchillo que no tuviese mella y la res no avia de ser trefe; e que avia de ser sacado de la dicha piema el dicho nervio largo, e que no se cunplia con la ley sy christiano matava la dicha res, e que pecava en la ley sy christiano la matava, porque no la podrían comer $^{76}$.

La carne trupha, trefé, trifá, trefa (< hebr. TEREFAH) es, pues, la no apta para el consumo por no haber sido sacrificada según las normas judaicas: ‘E después de desollada [...], Alonso Nuñes la cató e miró e dixo que no quería della, e este testigo e [...] Barahona dixeron que porque estava trefé la

75 P. LeÓN Tello, Judios de Toledo, I, doc. 49, a. 1412, $\$ 10$, p. 447. A principios del siglo xv aún se encuentra en las Biblias la variante fojaldres: «[...]: venga rruegote, Tamar mi hermana, \& faga delante mi dos fojaldres (O. H. HauptManN and M. G. LitTLEFieLD, Escorial Bible I.I.4, vol. II, "II Reyes", 13.6, p. 66). Según el DCECH (s.v. boja), fojaldres se documenta por vez primera en Alonso de Palencia (1490). Los ejemplos de fojaldres 1. ${ }^{2}$ parte del siglo $\mathrm{xv}$ - y de bojaldres - 1412 - hacen que estas formas sean, por el momento, las primeras documentaciones del vocablo.

76 -Tres precisiones de Alonso de Zamora ante el Tribunal de la Inquisición, Sefarad, 34 (1974), pp. 115-117. Para comprobar su complejidad, ver A. JUDERIAS, Viaje por la cocina Hispano-Judia. s.v. shejita. 
dexava" $\pi$; e non queria comer carne de la trefa por ser defendido a los judíos" ${ }^{78}$.

En algún documento, esta carne también apareció mencionada como pelaguda:

en el varrio de los Montoyas, en el qual dicho varrio biuia a la sason Juana Lopes la Rabeuera vieja..., [...], holgaua los sabados sin haser cosa alguna e se tocaua los tales dias tocados linpios, e que asy mismo non comia toçino, nin liebre, nin conejo, nin carne ninguna pelaguda... ${ }^{79}$.

Lo habitual en estos casos era comprarla en los mataderos y tiendas regentados por judíos. Si se tenía la certeza de que el animal no había sido sacrificado legalmente o se abrigaba alguna duda sobre ello, se abstenían de consumirlo:

E que este testigo degollo vn dia vn pollo, y que desque supieron que el le abia degollado, que non lo quisieron comer, e que le fisieron comer a este testigo e a vna canaria que estaba en casa. ${ }^{80}$; "Iten, que la dicha Maria Dias non comia came si non fuese muerta con çerimonia judayca o por mano de judio, e quando non la pudia auer non comia otra, saluo fruta e hueuos o semejante ${ }^{81}$.

Con razón dice Baer: "Por motivos rituales la existencia de panaderos y carniceros judíos era indispensable ${ }^{82}$.

Para evitar el fraude en la venta de carne, se dictaron una serie de leyes. En el Fuero de Plasencia se dice:

Si el carniçero carnes mortezinas, o de ganados en-/fermos o de puerco o carnes mestas - estas son carnes ca-/brunas con carnerunas $\longrightarrow$ carnes feridas o cames iudaycas -que dizen trupha o uiedras-, con rezientes touiere, peche .X. morauedís a los querellosos e a los mayordomos si fuere prouado ${ }^{83}$.

7 C. CARRETE PARRONDO, FIRC, II, doc. 345 , a. 1502 , p. 141 , lín. 3.

78 H. BEINART, Records, II, a. 1504, p. 152.

79 Y. MORENO KOCH, .La comunidad judaizante..., Sefarad, 37 (1977), pp. 366-79. Covarrubias (s.v. peliagudo) escribe: 'Se dize del cabrito, temero, conejo y otros animales semejantes'. El lexema también se encuentra en el Quijote (II, 47): "Vuesa merced tiene razón, señor gobernador, respondió el médico, y así es mi parecer que vuesa merced no coma de aquellos conejos guisados que allí están, porque es manjar peliagudo. (Manuel M. MARTINEZ Llopis, Historia de la gastronomía española, Madrid: Alianza, 1989, p. 263).

80 H. BeINART, Records, I, doc. 79, a. 1484, p. 482.

81 H. BeINART, Records, I, doc. 2, a. 1484, p. 49.

82 F. BAER, Historia de los judios en la corona de Aragón, p. 186.

83 M. ${ }^{2}$ Josefa POSTIGO ALDEAmIL, Edición y estudio del Fuero de Plasencia (Madrid: Servicio de Reprografia de la Universidad Complutense, 1984), 5653 , p. 263. La vigilancia del estado de la carne era una costumbre que ya se llevaba a cabo en Roma. Según 
De esta forma, el legislador trata de evitar que el carnicero venda como carne fresca la carne viedra (< VETERA) o carme cediza, esto es, la 'que empieza a corromperse' (DRAE, s.v. carne 1).

Por el derecho a vender, los dueños de las camicerías debían pagar una tasa o impuesto -que en Toledo recibió el nombre de almaguanas o almagonas - y con cuyo nombre fueron conocidos posteriormente dichos puestos de venta:

Las casas que el aljama de los judíos dio el cabildo en troque de los derechos que auía el cabildo en las carnescerías de los judíos, que disen almaguanas ${ }^{84}$; Este día Yuçaf carnicero de los judíos dio un diezmo en las almagonas de los judíos que llega a $130 \mathrm{mrs}$. sobre $100 \mathrm{mrs}$. en que fueron rematadas ${ }^{85}$.

Los animales destinados al consumo se sacrificaban haciéndoles una incisión en el cuello o laguilla, según se lee en un pasaje bíblico: ‘y rretuerçale la cabeça al cuello, y fagale vna laguilla al cuello, y faga correr la sangre en derredor del altar, ${ }^{86}$.

MARTínEZ LLOPIS, "Existía una policía para vigilar los mercados, que imponía fuertes multas a los tablajeros que vendían carne que llevara muerta más de cuarenta y ocho horas en inviemo y veinticuatro en verano" (Historia de la gastronomía española, p. 31).

84 P. LEÓN TELlo, Judíos de Toledo, II, doc. 942, a. 1460, p. 330. La palabra almaguana procede del árabe الهُؤَن/almu'an/ 'impuesto de aprovisionamiento', voz que

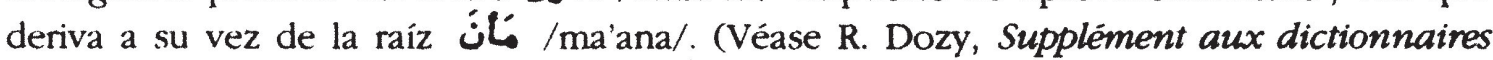
arabes (Leyden-Paris, $1967^{3}$ ), II, s.v. Ĺ . pp. 565-566). Sobre el impuesto de la almaguana, ver Miguel Ángel LADERO QUESADA, Granada. Historia de un país islámico (1232-1571) (Madrid: Gredos, 1969), p. 52 y A. LOPEZ DAPENA, "Las rentas de Guadix de 1494, 1501 y 1502", Cuadernos de Estudios Medievales, X-XI (1982-83), pp. 149-167, especialmente 151 y 157.

85 P. LEÓN Tello, Judíos de Toledo, II, doc. 778, a. 1432, p. 233.

* Biblia Romanceada I.I.8. The 13 th. Century Spanish Bible Contained in Escorial Ms. I.I.8 Edited by Mark G. Littlefield (Madison 1983), "Levítico* 1. 15, p. 1. Creo que laguilla es diminutivo de llaga (< PlaGA). Corominas y PAscual (s.v. llaga) le dan el significado de 'golpe', 'herida', acepción esta última la del texto. Nada indican, empero, de la posibilidad que la palatal lateral $/ /(<$ PL-, CL-) pueda simplificarse en $/ V$, por analogía. El resultado, sin embargo, no debió ser ajeno a los distintos dialectos: que te mande uenir de noche a estos locares lenos de miedo, e non uin yo primero (Alfonso El SABIO, General Estoria, Segunda parte I, edic. de A. G. Solalinde, Lloyd A. Kasten y Víctor R. B. Oelschläger, Madrid, 1961, p. 168). .et... dévenlo alimpiar la laga con un trapo de lino mojado en vinagre bien fuerte... (J. Manuel). La cita la tomo del DCECH, s.v. gormar, p. 177. "Estos son los nonbres de los fijos de Aaron el sacerdot que fueron vntados, de los quoales fueron las manos lenas \& conssegradas pora vsar el seruicio del sacrifficio- (Biblia Romanceada I.I.8, Numero 3.3., pp. 20-21). 4...] e estos dos notarios que tengan las laves de los seellos e que ayan las vistas de las cartas/ ${ }^{17}$ e que la nuestra chançelleria nos sea metida en arrendamiento" (M." Dolores GUERRERO LAFUENTE, Historia 
Acción posterior era la de purgar (< PURGARE) la carne, esto es, limpiarla de todo tipo de grasa, sebo, nervios, etc.: eque viviendo este testigo con Gómez Gonçález de la Hoz, difunto, [...], viera al dicho Gómez Gonçález mandar purgar la carne [...]. ${ }^{87}$; «quitándole todo el gordo o seuo segund e como los judios lo hazian" ${ }^{88}$.

Otra parte eliminada era el nervio conocido por landrezilla o langostilla. Según Covarrubias, 'Es cierto niervo viscoso que está en medio del muslo del animal, que por otro nombre le llaman la bava; tiene alguna gordura y en el carnero será de cantidad de una nuez pequeña o una avellana, la qual landrecilla los judíos la sacan de la pierna del carnero, y no la comen en memoria de avérsele secado a Jacob aquel niervo [...]' (s.v. landrecilla), y el DRAE (s.v. landrecilla) 'Pedacito de carne redondo que se halla en varias partes del cuerpo' ${ }^{89}$.

En los textos no faltan testimonios:

... vio [...] que purgaua la carne quitándole el seuo, e que sacaua la landrezilla de la pierna del carnero; e que vio este testigo que vn domingo se tenía hecho vna adafina

de la ciudad de Benavente en la Edad Media. Colección diplomática del archivo municipal de Benavente (Zamora). Estudio bistórico, paleográfico, diplomático y lingüístico, Benavente, 1983, doc. VIII, a. 1295, p. 445). "Preguntado que commo lo sabie, dixo que porque tenie las laues de los troxes e la vna del yta. (Araceli CAstro Garrido, Documentación del monasterio de las Huelgas de Burgos (1307-1321). Burgos, Ediciones J. M. Garrido Garrido, 1987 , doc. 242, a. 1312, p. 89, lín. 27). uet la haça de la tierra de la serna que lega al espinnom. A. CASTRO GARRIDO, Documentación del monasterio de las Huelgas de Burgos (1307-1321), doc. 237, a. 1311, p. 79. lín 4, etc. En el Fuem de Plasencia (a. 1297), se lee: ‘Los maestros de las teias e de llols ladriellos fagan las teias dos palmos en luengo, en en ancho palmo e medio, e en cabo palmo e mano. Et en gordo aya quanto de la oreia del polgar fas-/ta el somo. Et sean bien cochas, que yelo o luvia non las desate* (Fuero de Plasencia, Ley X.", p. 262, \$ 652). Y como luvia 'lluvia' se conserva en judeoespañol (véanse Joseph NEHAMA, Dictionnaire du Judér-Fspagnol. Avec la collaboration de Jesús Cantera, Madrid, CSIC, Instituto "Benito Arias Montanom, 1977, s.v. luvia; A. ZAMORA VICENTE, Dialectología española, Madrid: Gredos, 1967, p. 356). Idea bastante generalizada, que no comparto, es creer que la $l$ procedente de los grupos consonánticos citados es una grafía que representa el sonido $[l]$. (Entre otros, véase Máximo TORREBlanCA, :La evolución /kl, pl-, fl-/ > /1/ en español", RFE, LXX (1990), pp. 317-327, especialmente p. 320).

87 C. CarRete ParRondo, FIRC, III, doc. 140 , a. 1489 , p. 80 , lín 5.

8 H. BEINART, Records, II, a. 1511, p. 248.

89 En el Diccionario de NEBRIJA titulado Dictionarium AElij Antonij Nebrissensis Jam denuo innumeris dictionibus locupletatum, Antvrpiae, In aedibus Iohannis Steelsij, Anno a Christo nato, MDXIV, mense lunio, se dice s.v. Adénes: *Adénes dnr glandule sub ala \& inguine. lãdrezillas". COROMINAS-PASCuAL (s.v. landre) lo recogen como 'pestecita' en la Celestina empleado a modo de insulto cariñoso. 
guisada ${ }^{90}$; no comía tocino ni consentía glulisallo en su casa e no comía de manjar que fuese con ello glulisado, y la bio osensebar [sic] la carne e sacar la langostilla de la pierna del carnero ${ }^{91}$.

Los alimentos permitidos recibían el nombre de caser ( $<$ heb. kaser), voz que alguna vez aparece castellanizada como casero y caseres: ‘E que otros días comió con este testigo e con el dicho [fol. 938r] su marido de sus viandas e manjares caseres. "22; "e bebían del bino casero [sic], e deçía burlando uno: 'cabri mananar', que es la bendición del bino de los judíos" ${ }^{93}$.

Como fieles seguidores de los preceptos judíos, los judaizantes tampoco permitian que personas ajenas a su religión guisaran en sus ollas ni bebieran en el mismo recipiente. De no haber más remedio, había que fregarlos previamente a fondo: "Y el tenia aparte olla en que guisava de comer, y el se lo guisava y no queria que ninguno llegase [a] su olla, y el llevaba vna calderuela de çofar pequeña con que bebian ${ }^{94}$; "... e para los moços e moças tenían unas vasyjas a parte a cabsa del toçino que no lo comían, e quando las moças lo comían les fazían fregar las manos e con salvados, e que aun no querían tomar una jarra de agua dellas syn que se fregasen" $"$.

\section{COSTUMBRES FUNERARIAS}

Otro de los actos rituales eran los llamados cogüerços 'convites fúnebres' ${ }^{\text {'. }}$. Según la costumbre judía, durante los siete días de duelo -con excepción del sábado- los dolientes se sentaban en el suelo mientras los

To C. Carrete Parrondo, FIRC. II, doc. 19, a. 1490 , p. 28 , lín. 3.

91 C. Carrete Parrondo, FIRC. III, doc. 64, sin año, p. 42, lín. 5. Langostilla. diminutivo de langosta (< LACUSTA), se emplea como sinónimo de landrecilla.

92 C. Carrete. Parrondo, FIRC, III, doc. 3, la. 1490], p. 18, lín. 8. El plural es totalmente romance.

93 C. CarRete Parrondo, FIRC, III, doc. 182, a. 1486, p. 103, lín. 6. En la línea 11 aparece de nuevo casero.

94 H. BEINART, Records. I, doc. 14, a. 1484, p. 267.

95 N. LOPEZ MARTINEZ, Los judaizantes castellanos... El texto se encuentra en la p. 184, nota 161 .

* Según el DCECH (s.t. cogorza), procede de un vulgar CONFORTLARE, cuya primera documentación recoge GARCÍA DE DIEGo bajo confuerço en las Cortes de Valladolid (1258). Diego CataláN, El español. Orígenes de su diversidad (Madrid: Paraninfo, 1989), p. 284, cita el mismo texto de las Cortes en donde, sin embarrgo, aparece cohuerços: -nynguno non faga cofradias... synon... para soterrar muertos o para cobuerços que se coman en casa de los muertos". 
familiares se encargaban de proporcionarles los alimentos de los que preceptivamente se excluía la carne: "Yten, que el dicho Iohan de Chinchilla fue en faser coguerços, e comio en ellos çerimonialmente las viandas e cosas que en tal caso comen los judios" ${ }^{97}$; "Iten, dixo que algunas veses comio a los cohuerços en Almodovar, en casa de Çuçen, en el suelo, en modo judayco, e que los abades comian gallinas a su mesa y los conuersos en el suelo garuanços e hueuos" ${ }^{9}$; "E costo pan e vino e carne el dia que lo enterraron para comer el cobuerco [...]" "9; "cuando murió su madre en toda la semana no comieron carne, sino pescado, y no vebieron del agua que estava en casa el dia en que ella murión ${ }^{100}$.

Acción que también llevaban a cabo los amigos y vecinos durante los días de luto ${ }^{101}$ : "Diego Delgado enbió a este testigo con vn presente de dos pares de capones e vn plato grande de avellanas e higos e dátyles a [...] Gonçalo Sanches al qual se le avía muerto la muger pocos días avía" ${ }^{102}$.

Según Molho, práctica habitual era también vaciar los depósitos de agua de la casa en que una persona había muerto: derramava el agua quando alguno falleçia e estava çiertos dias despues del falleçimiento del defunto que no comia carne, como lo hasen los judios, que estava tras la puerta" ${ }^{103}$.

Su origen tiene lugar, según este autor, en sla creencia de que el ángel de la muerte limpia su espada mortífera en las aguas que encuentra a su alcance, después de haber realizado su letal acción.

Por otro lado, era frecuente colocar una vasija de agua en la habitación donde estaba el muerto como medida de protección contra los malos espíritus: «e puso escudylla con agua en el lugar donde moryan e vnas tovajas e vna aguja con salamar e candyles ençendidos" ${ }^{104}$.

La muerte de una persona era anunciada por las mujeres de la familia con gritos de dolor a las que se sumaban plañideras o endechadoras. Por ello no es extraño encontrar a una tal doña Nabila reunida con judías. y conversas srabiça

97 H. BeINART, Records, doc. 7, a. 1483, p. 165, lín. 31.

98 H. BEINART, Records, I, doc. 7, a. 1484, p. 176, lín. 26. Según BAfr, Historia de los judios, II, p. 586, era también práctica habitual en los duelos alimentarse de pescado.

99 Eliseo SÁNZ RIPA, Colección diplomática de las Colegiatas de Albelda y Logroño (Tomo I: 924-1399) (Logroño: CSIC, Instituto de Estudios Riojanos, 1981), doc. 231, a. 1380 , p. 387 , lin. 11.

100 Y. MORENO KOCH, «La comunidad judaizante..., Sefarad. 37 (1977), p. 353. Según la autora, la costumbre de no beber agua se propagó también entre los cristianos viejos.

101 Para más detalles de las costumbres en otros lugares, véase la obra de M. MOLHO, Usos y costumbres..., pp. 188-189.

102 C. CARRETE PARRONDO, FIRC, II, doc. 368, a. 1502, p. 152, lín. 16.

103 M. MOLHO, Usos y costumbres... op. cit., p. 174. Y. MORENO KOCH, .La comunidad judaizante..., Sefarad, 37 (1977), p. 366.

104 H. BEINART, Records, II, a. 1495, p. 65. 
dellas que estaua vestyda a forma de rabi, e con ellas oya e rezaua sus oraçiones sobre los muertos, endechandolos e dandose con las manos en las rodillas y en la cara, e respondiendo a lo que la rabiça rezaua e dezia" ${ }^{105}$.

Costumbre ritual era igualmente bañar a sus muertos antes de amortajarlos para proceder a su inhumación. Por ello, los bañadores de los muertos se dedicaban con esmero y especial celo a cumplir con este acto que, sin embargo, debió de estar prohibido durante algún tiempo por cuanto en una orden dada en Zaragoza se permite que los judíos "puedan fazer e banyar a los ditos judios quando sian finados e levar en el cuello al fossar pora enterrarlos, [...], clamado en hebrayco Noze Amita ${ }^{106}$, cuyo fin -el de la asociación Nozéamitá - era el traslado de los cadáveres hasta el cementerio ${ }^{107}$.

Según un texto aragonés del siglo xv, los bañadores de los muertos veían su humanitaria misión recompensada con la exención de pagar determinados tributos a la aljama, aunque no eran los únicos. Entre los beneficiarios de tales exenciones tributarias se contaban "Los sabios que son preycantes [...] e los que cantan en la sinagoga e los banyadores de los muertos ${ }^{108}$; costumbre que, según Molho, aún perduraba en la comunidad sefardí de Salónica ${ }^{109}$.

Muchos judeoconversos fueron en ocasiones acusados de llevar a cabo estas prácticas rituales, tal y como ordenaba la Ley de Moisés, al haber participado en alguno de estos actos. En un proceso alguien confiesa que se "le mandara poner vna poca de agua a callentar e echar çeuada dentro e, despues de caliente el agua, mandara traer vnas tablas e vna artesa e lo sacaran de alli e lo vañaran la dicha Juana Lopes e este testigo e las dichas otras moças del dicho defunto [...]; e despues de asy vañado, le pusieron sobre las tablas e le vistieron vna mortaja sobre vn sant benitillo largo* ${ }^{110}$.

Los muertos solían ser enterrados en tierra y sobre su fosa colocaban una lápida que recibía el nombre de piedra jabaluna, como bien prueba el siguiente fragmento: «En 3 de julio compraron del jurado Alonso de Açafran, vezino de Toledo, 300 piedras jaualunas de las del hosario de los judíos ${ }^{11}$.

105 F. Cantera Burgos y C. Carrete Parrondo, "Las juderías medievales en la provincia de Guadalajara", Sefarad. 34 (1974), pp. 43-78. La cita se encuentra en las pp. $76-77$.

10* A. Bl.Asco Martínez, Los judios de Zaragoza, VII, doc. 247, a. 1387, p. 663, lín. 10.

10- A. Blasco MARtinez, La juderia de Zaragoza. p. 19, dice que Nozé-amitá es el "Nombre de una cofradía que se ocupa de transportar los cadáveres hasta el cementerio".

10 Francisco BALAGUER, "Notas sobre la población judía de Huesca en el siglo XV", Sefarad. 45 (1985), pp. 341-351. La cita se encuentra en la p. 343, n. 3.

109 Cf. Usos $y$ costumbres, pp. 175 y ss.

110 Y. MORENO KOCH, "La comunidad judaizante...", Sefarad. 37 (1977), p. 366.

11 P. LEÓN TEllo, Judíos de Toledo, II, doc. 1697, a. 1494-1495, p. 598, lín. 4. El DCECH (s.t' jabalin afirma que jabaluno se documenta en Córdoba en 1737. Como 
En cambio, toda fiesta o celebración no funeraria recibía el nombre de añazea: sabe e vido que guardavan y andavan en añazeas como dia de fiesta e mercavan barro nuevo para aquella fiestan ${ }^{112}$.

\title{
OTROS ACTOS RITUALES
}

Una voz muy común entre los judíos es meldar. El vocablo, que ha tenido las acepciones de 'estudiar', 'enseñar' y 'leer hebreo', entre otras, lo deriva el DCECH (s.v. meldar) del lat. tardío MELETARE. Leo Spitzer ${ }^{113}$, siguiendo a Gaspar Remiro para quien meldar procede del hebr. melmed (< lamed 'en-

\begin{abstract}
jabaluna se encuentra en un texto de finales del siglo $\mathrm{xV}$, hay que considerarla, por el momentc, como la primera documentación del término. Antonio AlCalá VencesLadA, Vocabulario Andaluz (Madrid: Gredos, 1980) s.v., define el sustantivo jabaluno como 'Piedra caliza que se cuece para obtener cal'. Del adjetivo jabaluna se dice: 'Piedra blanca de gran dureza'. También se conoce por jabaluna un determinado tipo de aceituna. El DRAE, s.v. piedra, la define como 'piedra caliza de color obscuro, como el del jabalí, cuando está mojada', indicando que es voz propia de Andalucía. En el artículo de Elena ROMERO, "La última jornada del hombre en una copla sefardí de moral", Sefarad, 40 (1980), pp. 403-417, se encuentra la siguiente estrofa:
\end{abstract}

15] El arón le atan cuedra sobre cuedra como que se fuye y sale afuera, meterán a él una buena piedra; quen y quen vendrá a tocar el palo como que lo llevan a buen balo. (p. 409).

La autora - para quien arón $=$ féretro y balo = baile- dice que la colocación de la lápida en el sepulcro -idea ofrecida en el tercer verso- parece tener la finalidad de evitar la fuga del muerto. Entre los cristianos, la lápida recibía el nombre de piedra de sobrefuesa: "dedes e fazedes donaçion a nos, los dichos Andres Gonzalez e Maria Ferrandez, de una fuesa con su piedra de sobrefuesa, que es en la claustra del dicho monesterio. (F. Javier PEÑa PÉREz, Documentación del monasterio de San Juan de Burgos (1091-1400), Burgos, ediciones J. M. Garrido Garrido, 1983, doc. 155, a. 1371, p. 271, lín. 2. De nuevo se menciona en la p. 276 , lín. 32.

112 H. BEINART, Records, I, doc. 77 , a. 1484 , p. 456. El DRAE, que considera el vocablo como antiguo, lo deriva del ár. an-nazaba 'el recreo, la diversión'. K. NEuvonen, Los arabismos del español en el siglo XIII (Helsinki, 1941), s.v. annaze(b)a, p. 235, afirma que la voz no era habitual en castellano medieval excepto en las obras literarias Crónica General, General Estoria y Conquista de Ultramar. COROMINAS-PASCuAl, s.v. añacea, defienden, en cambio, su común empleo, como bien demuestra el texto.

113 Judéo esp. •meldar, RFE, VIII (1921), pp. 288-291. J. NeHAMA, Dictionnaire, s.v. meldár, dice que significa 'leer, estudiar y consultar libros'. Véanse también Mariano GASPAR REMIRO, Sobre algunos vocablos y frases de los judeo-españoles", BRAE, II (1915), pp. 294-301, especialmente s.v. meldar, p. 296 y ss.; Alan D. CORRE, "A Comparative Sephardic Lexicon", Hispania Judaica. III, pp. 39-59, especialmente p. 51. 
señar'), se pregunta por el proceso seguido desde 'enseñar' a 'orar'. Según él, los niños aprendían a leer en la lengua hebrea de sus antepasados y no en su lengua familiar, porque para ellos leer es rezar. De este modo, la instrucción primaria de los niños se concibe no sólo como iniciación a la lectura, sino también como práctica religiosa.

La forma meldar de los siguientes pasajes hay que interpretarla como 'leer' y 'rezar a la manera judaica': «quel dicho Ruiy Martines que se entraua por las sinagogas desta [...] çibdad e rezaua oraçiones de los judíos en las mismas synagogas, meldando como los otros judíos" ${ }^{114}$; "a los quales falló este testigo leyendo sobre unos libros, meldando e sabadeando, e leyan en voz, que los oyó bien este testigo" ${ }^{115}$.

Al aparecer en los textos el lexema sabadear unido a meldar y rezar, estimé que sabadear -voz que no he hallado en ninguna de las obras lexicográficas consultadas- probablemente significara el movimiento de cabeza con que se acompañan los judíos al tiempo de sus plegarias, como bien parecen indicar algunos textos: «e que lleuaua en la mano vn ramo de salze [sic] verde, e que yua rezando e sabadeando "116; "Antes que comiese tomaua una correa e se la echaua al pescueço e se la ataua a los dedos, e sacaua vna cartilla estrecha, tan larga como palmo e medio [...], e la leya e resaua, estando de cara a la pared, e llegando algunos pasos de la dicha oraçion sabadeaua como judio con la cabeça " 117.

Pero más preciso aún es el siguiente testimonio: «e vio este testigo cómo Fernand Aluares estaua asentado a los pies de la [...] cama e sabadeando, alçando e abaxando la cabeça, como lo fasían los judíos, e le oya, quando sabadeaba, que desya: 'Baha' e otras palabras que no le entendía" ${ }^{118}$.

Un acusado de judaizar -Pedro García Torrillo- a quien se le imputa, entre otras cosas, de sabadear responde en su defensa que alzar y bajar la cabeza, *avnque sea mala costumbre, no es çerimonia judayca" ${ }^{119}$.

114 C. Carrete Parrondo, FIRC, II, doc. 12, a. [1490], p. 24, lín. 7. Sobre los significados de meldar en el judeoespañol de Marruecos, véase el artículo de Carlos BENARROCH, "Ojeada sobre el judeoespañol de Marruecos", Actas I Simposio de Estudios Sefardies, p. 268, nota 13.

115 C. Carrete ParRondo, FIRC. III, doc. 117 , a. 1489 , p. 68 , lín. 12 . De nuevo en la lín. 15.

116 C. CARRete ParRondo, FIRC, II, doc. 41, a. 1490 , p. 34, lín. 7.

11 Y. MORENO KOCH, :La comunidad judaizante...*, Sefarad, 37 (1977), p. 367. Aunque la confesión del testigo tiene lugar en 1490 , lo denunciado hace referencia a hechos acaecidos en 1488.

118 C. CARRETE PARRONDO, FIRC, II, doc. 254, a. 1501, p. 114, lín. 15. Según Carrete, babá procede del heb. bakab 'lloro, lamentación'.

119 F. Cantera Burgoos y C. CARrete Parrondo, slas juderías medievales..., Sefarad, 134 (1974), pp. 342-343. 
El RITUAL DE PONER NOMBRE A LAS HIJAS

Motivo de particular regocijo y fiesta era el rito de poner nombre a la hija que acababa de nacer, acto religioso conocido por fadar. Item la septena noche de el nacimiento de la criatura ponen un bacín con agua, y echan en él oro, plata, aljófar, trigo, cebada y otras cossas, y lavan allí las criaturas diciendo ciertas palabras; y esto se llaman las hadas que hacen a las criaturas" ${ }^{120}$; :Iten, que fiso badas a sus fijos como lo fasen los judios a sus fijos al tienpo de sus naçimientos" ${ }^{121}$.

Concluida la ceremonia con la bendición de la recién nacida por el rabino, los asistentes, que también habían deseado salud y larga vida a la nueva criatura, eran agasajados por los padres con un banquete en donde no faltaba la diversión ${ }^{122}$ : “y venian alli donzellas e otras sus parientas e tañian alli los panderos e comian frutas y alli hasian las hadas. ${ }^{123}$.

\section{ACTITUD DE LOS JUDAIZANTES}

En los juicios inquisitoriales, la persona tachada de judaizante se defiende de su acusador preguntándole a su vez si lo vio celebrar alguna vez el ritual de las fadas o hadas: "Yten, sy saben, etç., que al tienpo que alguno de los fijos que yo tengo nasçieron yo non los fade ni mande fadar, et sy se fadaron, que los mandaria e faria fadar Iohan Gonsales Panpan, su padre" ${ }^{124}$.

Se sabe también que muchos de ellos habían fingido su conversión al cristianismo con el fin de eludir el tormento que le llevara a renegar de su fe o, en el peor de los casos, el ser condenado a la máxima pena y, por ello, ser quemado. De ahí la patética confesión de una acusada: "e que se

120 N. LOPEZ MARTINEZ, Los judaizantes castellanos..., p. 173, nota 113.

121 H. BeInART, Records, I, doc. 3, a. 1483, p. 73, lín. 39. Según J. Nehama, Dictionnaire, s.v. fadár, a los hijos varones se les ponía el nombre en el momento de la circuncisión. Fadár. según Nehama, significa 'destino, suerte, encantamiento'. Para R. LAPESA, Historia de la Lengua Española (Madrid: Gredos, 1980'), p. 528, fadar 'destinar, lograr'. COROMINAS-PASCUAL indican que hado 'predicción, oráculo', 'destino, fatalidad', deriva de FATUM < FARI 'decir', cuya primera documentación se halla en Berceo. Ambos autores advierten que en la época medieval era más frecuente el empleo de hada que hado; será en el Renacimiento cuando se imponga el masculino.

122 Para más detalles, véase Michael MolHo, Usos y costumbres..., pp. 79-81.

123. H. BEINART, Records, I, doc. 77, a. 1484, p. 456.

124 H. BEINART, Records, I, doc. 3, a. 1483, p. 77, lín. 6. Sobre los procesos de la Inquisición en Ciudad Real, consúltese la obra de BAER, Historia de los judíos en la España cristiana, pp. 574 y ss. 
avia reconçiliado porque non la quemasen, que mas queria verguença o bermejuela en cara que manzilla en coraçon " ${ }^{125}$.

En otras ocasiones, la persona declara su falta confesando vivir en privado como judío y en público como cristiano: ‘Digo más mi culpa: que una fija que me nasçió le consentí faser fadas e quando murio le fesimos su mortorio e amortajáronla e enterráronla en sant bartolomé " ${ }^{126}$.

Actitud, por otro lado, muy frecuente por cuanto no era extraño llevar a bautizar al hijo y, una vez en la casa, se cuidaba de limpiar el crisma con el que había sido ungido hijo de la Iglesia: "los que podían escusarse de no baptizar sus fijos, no los baptizaban, e los que los baptizaban, lavábanlos en casa desque los traían" ${ }^{127}$.

Por ello no debe sorprender que muchos cristianos creyeran que los conversos iban "tomando nombres de christianos por cumplir con el mundo y engañar las gentes y en secreto llamando vos de nombre hebrayco como lo facen los otros maranos hebreos" ${ }^{128}$.

Un ejemplo esclarecedor nos lo ofrecen los siguientes testimonios: "vio cómo Catalina [...], venía disiendo a vn su fijo: 'Juanico, fijo', e como no le respondió dixo por dos o tres veses la susodicha a [...] su hijo: 'Araquigüelo'. "29; "Garçía Ferrandes dixo a vn su fijo: 'Alonsyto, ve por el Tangún -ques vn libro de la ley de los judíos-, que quiero meldar'; e quel moço le respondió: ‘Llamáysme Alonsyto y enviáysme por el Tangún?. 130.

\section{El CUMPLIMIENTO DEL SÁBADO}

El sábado, fiesta de precepto del pueblo hebreo, estaba prohibido guisar, limpiar, realizar ejercicio físico, coger dinero, etc. Era, pues, un día de descanso del quehacer diario y día destinado a visitar a los familiares y amigos, para lo cual se acicalaban y vestían sus mejores galas: ‘Sabe e vido [...] que guardauan el sabado madre e hijas e se vestian de fiesta aquel dia e se afeitauan" ${ }^{131}$.

125 H. BEINART, Records, II, a. 1511, p. 77. Vuelve a repetirse bermejuela en las pp. 87 y 90. Según el DCECH (s.v. bermejo), bermejuela se documenta por vez primera en 1535. La forma del texto sería, pues, veinticuatro años anterior $y$, por tanto, la primera datación provisional del vocablo.

$12 \%$ N. LÓPEZ MARTínez, Los judaizantes castellanos... Apéndice VI, “Una declaración de Juan de Sevilla*, a. 1486, p. 410.

127 N. LOPEZ MARTINEZ, Los judaizantes castellanos... p. 177, nota 125.

128 N. LOPEZ MARTINEZ, Los judaizantes castellanos... Apéndice II, .Traslado de una carta de privilegio que el Rey Don Juan II dio a un hijo dalgo, pp. 382-387. El texto de la cita se encuentra en la p. 386.

129 C. CARRete PARRONDO, FIRC, II, doc. 251, a. 1501, p. 113, lín 5.

130 C. CARrete PARRONDO, FIRC, II, doc. 113, a. 1491, p. 62, líns. 5 y 6.

131 H. BeINART, Records, I, doc. 2, a. 1484, p. 55, lín. 27. 
Para estar dispuestas el sábado, la noche de los viernes las mujeres llevaban a cabo un baño o inmersión ritual conocido con el nombre de tibulá $(<$ heb. tebilab): e dixo a su madre: 'Dónde his [sic] a tal ora?', a lo qual respondió: 'Calla, no digas nada, que bamos al baño donde se faze la tibulá. 132 .

El baño se preparaba con cuidadoso esmero; su atención llegaba al extremo de procurar que el agua - cuando se bañaban en la casa- estuviera no sólo caliente, sino incluso perfumada con plantas aromáticas: manzanilla, romero, gramonilla, flor de saúco, espliego, etc.: hazia calentar agua con romero e cascaras de naranjas" ${ }^{133}$; $\mathrm{E}$ aquellas noches de viernes [...] se vañavan [...] en vna tinaja grande con agua cozida con yerbas, manzanilla e otras yerbas. ${ }^{134}$.

Tanta exquisitez, empero, no era posible cuando debían desplazarse a los baños públicos: "esta confesante se vaño en su casa [...], e [otra vez] en el vaño de la çibdad vn sabado en la noche por çerimonia judayca" ${ }^{135}$.

Del empleo de ciertas yerbas para el baño y para los afeites de la mujer dan buen testimonio algunas obras literarias: "Aparejos para baños, esto, es una marauilla, de las yeruas e rayzes, que tenía en el techo de su casa colgadas: mançanilla e romero, malualiscos, culantrillo, coronillas, flor de saúco e de mostaza, espliego e laurel blanco, tortarosa e gramonilla, flor saluaje e higueruela, pico de oro e hoja tinta" (La Celestina, XX, 78); "Laurel blanco, gramonilla,/ flor salvaje e higueruela,/ aceites para la cara,/ de jazmín, limón, violeta,/" (A. Rojas Villandrando, El viaje entretenido) ${ }^{13.6}$.

Como el sábado era día festivo y de total descanso para los judíos, su inactividad llegaba hasta el extremo de no poder apagar los candiles. Las voces empleadas para describir esta acción eran apagar, amatar e incluso morir: *e que aquellos candiles la dicha noche los ponia en çierta parte de su casa e no los amataua fasta que ellos mismos se amatanan e apagauan de suyo. ${ }^{137}$.

132 C. Carrete Parrondo, FIRC, doc. 81 , a. 1487 , p. 51 , lín. 31. En H. Beinart, Records, I, pp. 239 y 243, aparece como tibila.

133 H. BEINART, Records, II, a. 1511, p. 263.

134 H. BEINART, Records, II, a. 1512, p. 274 . Sobre el empleo de plantas para el baño, véase la obra de Jesús Terrón GONZÁlez, léxico de cosméticos y afeites en el Siglo de Omo (Universidad de Extremadura: Servicio de Publicaciones, 1990), s.v. gramonilla y tortarosa.

135 H. BeINART, Records, II, a. 1512, p. 427.

136 Ambos fragmentos los he tomado de J. TERRÓN GONZÁlfz, Léxico de cosméticos, s.v. gramonilla. p. 121.

137 H. BEINART, Records. II, a. 1511, p. 247. En el siglo XVII aún perdura matar 'apagar', como bien se aprecia en la siguiente estrofa de Juan de Salinas (1559-1643):

¿Qué puede hacer más

que darle polainas,

poniendo a sus puntas

encaje y holanda,

cocerle su came 
La situación llegaba hasta el punto de no apagar el fuego en caso de incendio: ay tanta devoçion tenia de aguardar el Dia Mayor y no le quebrar que en vn dia de aquellos se le enpeçaron a quemar vnos manteles e, por no quebrar aquel dia, teniendole por tan santo, non los quiso matar y los dexó arder como judio muy devoto de la ley de Moysen " ${ }^{138}$; o de no pagar la consumición de las bebidas en las tabernas ${ }^{139}$.

El domingo, en cambio, era un día laborable, circunstancia que aprovechaban los cristianos para acusarlos de incumplimiento del día sagrado: e les vido los domingos que se levantavan do mañana e les veya, entrando alla los domingos, posadas de mañana e las ruecas cabo ellas con sus çerros puestos ${ }^{140}$.

Para terminar, quisiera que estas líneas sirvieran de sincero y respetuoso homenaje a un pueblo que, despreciado y vejado, no sólo no abominó del país que lo expulsó de su tierra, sino que mostró su grandeza al transmitir a las sucesivas generaciones sus ancestrales costumbres y recuerdos, y lo que siempre fue vínculo de unión espiritual con su añorada Sefarad: la lengua.

\section{JOSÉ M. ${ }^{\text {a CHAMORRO MARTÍNEZ }}$ \\ Universidad de Granada}

Los documentos de los procesos inquisitoriales nos muestran algunos aspectos del sistema de vida de los judeoconversos: tipos de comida, costumbres, ritos religiosos y profanos, actitud ante la muerte, etc. Junto a todo ello, analizamos algunos problemas lingüísticos del léxico.

The documents of the inquisitorial trials reveal some aspects of the life style of the converted Jews: types of food, customs, religious and secular ceremonies, their attitude to death, etc. In addition, we also analyze some linguistic problems concerning the lexicon.

\section{y hacerle su salsa, encender su vela de noche sin llama; y en dándole gusto, soplar y matarla? \\ ¿Mal haya quien fia de gente que pasa!}

(L. Rosales, Poesía Española del Siglo de Oro, núm. 95, p. 86). Para mayor abundancia de datos sobre la guarda del sábado, véase N. LOPEZ MARTínEZ, Los judaizantes castellanos..., pp. 178-179.

138 Y. MORENO KOCH, .La comunidad judaizante..., Sefarad, 37 (1977), p. 367.

139 Cf. M. Molho, Usas y costumbres.... p. 212.

140 H. BEINART, Records, I, doc. 3, a. 1483, p. 83, lín. 30. El DRAE (s.v. cerro 4), lo define como 'Manojo de lino o cáñamo, después de rastrillado y limpio'. El DCECH (s.v. cerda) documenta la voz en el siglo XIv. 